\title{
AN EXPERIMENTAL STUDY ON A BUS AIR CONDITIONER TO DETERMINE ITS CONFORMITY TO DESIGN AND COMFORT CONDITIONS
}

\author{
Şaban Ünal* \\ Keywords: Bus Air-Conditioning, Cooling Load, Thermal Sensation, Comfort Conditions
}

\begin{abstract}
The air conditioning system for a bus should be selected considering a number of parameters, including passenger capacity, local climatic conditions, and fuel consumption. It is possible to determine whether a selected air conditioning system provides desired performance through testing. This study examines how to verify experimentally whether a bus air conditioning system meets design and comfort requirements. An experimental study was conducted on a prototype bus and was tested when driving on the Adana-Ceyhan highway in Turkey. The internal and external temperatures, evaporator inlet and outlet temperatures and relative humidity values were measured. Thermal sensation values were calculated by using empirical correlations given by ASHRAE. Furthermore, the instantaneous cooling load of the bus was obtained according to the experimental data, and the results are compared with the calculated cooling load of the bus by using the radiant time series method provided by ASHRAE. With respect to the obtained results, the selected air conditioning system conformed to design and comfort requirements.
\end{abstract}

\section{TEST SETUP AND METHOD}

A bus operates in different climatic conditions; therefore, testing of a bus air conditioning system should be performed in appropriate locations relative to expected climatic conditions. Intercity buses may be parked under the sun for a long time before travelling. In this case, the internal temperature of the bus can reach by $60^{\circ} \mathrm{C}$. However, upon travel commencement, the internal temperature and humidity of the bus are expected to reach desired comfort conditions in a short timespan once the air conditioning is switched on. In this work, an experimental study was performed to determine whether the air conditioning system installed on a prototype bus meets actual design and comfort requirements. The prototype bus is $12.8 \mathrm{~m}$ in length and has a 61 passenger capacity with two additional staff. For this study, necessary preparations were made according to the air conditioning test procedure of the bus manufacturer. Before the test, gas leakage of the bus air conditioning system was checked, as was the amount of refrigerant in the air conditioning system. After passing these checks, the bus air conditioning system was cleared for testing.

K-type thermocouples, a hygrometer, and an anemometer were used for the temperature, relative humidity, and air velocity measurements, respectively. The measured values of temperature and relative humidity were recorded periodically by using a data logger. Air velocities at the evaporator outlet were measured for each blower speed. The characteristics of the measuring devices used in the experimental study are given in Table 1.

Table 1 Characteristics of the measuring devices

\begin{tabular}{|l|l|l|l|}
\hline Measured Variable & Measuring Device & Range & Accuracy \\
\hline Temperature & K-Type thermocouple & $-50 / 100{ }^{\circ} \mathrm{C}$ & $\pm 0.3^{\circ} \mathrm{C}$ \\
\hline Relative humidity & Hygrometer & $+5 /+95 \%$ & $\pm 2 \%$ \\
\hline Air velocity & Anemometer & $0 / 40 \mathrm{~m} \mathrm{~s}^{-1}$ & $\pm 2 \%$ \\
\hline
\end{tabular}

K-type thermocouples were calibrated to provide an accuracy of $\pm 0.3^{\circ} \mathrm{C}$ for the temperature range of $-50 / 100^{\circ} \mathrm{C}$. According to the manufacturer's technical data sheets, the accuracy of the hygrometer used to measure relative humidity is $\pm 2 \%$ for the range of $+5 \% /+95 \% \mathrm{RH}$. A vane type anemometer was used to measure of the air velocity. The measurement range of the anemometer is $0 / 40 \mathrm{~ms}^{-1}$ and has an accuracy of $\pm 2 \%$ for this range.

This paper was recommended for publication in revised form by Regional Editor Tolga Taner "Osmaniye Korkut Ata University, Department of Mechanical Engineering, 80000 Osmaniye, Turkey E-mail address: saban.unal@osmaniye.edu.tr 
The internal and external temperatures measurement locations are shown in Fig. 1 schematically. External temperatures were measured on the left and right sides of the bus. Measuring points of the external temperature were located at near the outside mirrors. They were indicated as $T_{1}$ and $T_{2}$ in Fig. 1. Thermocouples for the outside temperature were positioned behind a windbreak for not to be affected by air flows while the bus moving. Also, the internal temperature measurement locations are indicated as $T_{3} \sim T_{12}$ in Fig. 1. Thermocouples used to measure the internal temperature were located at the passenger seat cushions approximately $900 \mathrm{~mm}$ above, and they were positioned not to be affected by the sun.

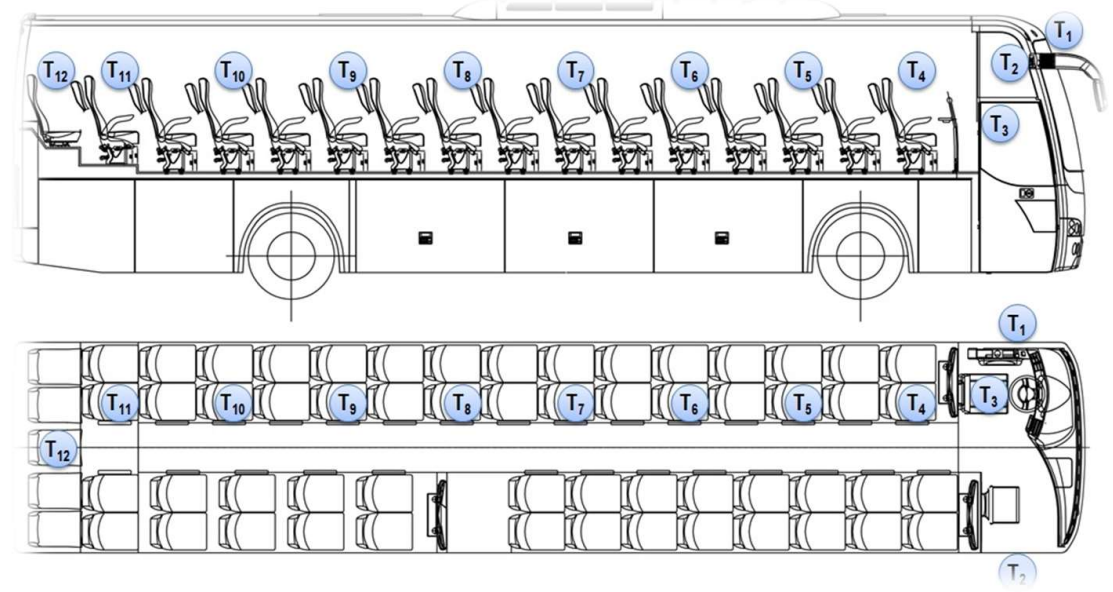

Figure 1. Internal and external temperature measurement locations

Evaporator units are located on the left and right sides of the bus. Air temperature and relative humidity values at the evaporator inlet and outlet were measured to determine the cooling load of the air conditioning system. The experimental study was started after preparation of the relevant sensors and equipment. At the beginning external temperature was measured by $33^{\circ} \mathrm{C}$ and with the air blowers set at maximum speed. Testing was performed with three test personnel on a route from Temsa to Yilankale back to Temsa at a constant speed of $90 \mathrm{kmh}^{-1}$. The study started at 1:00pm, and it was completed in 120 minutes.

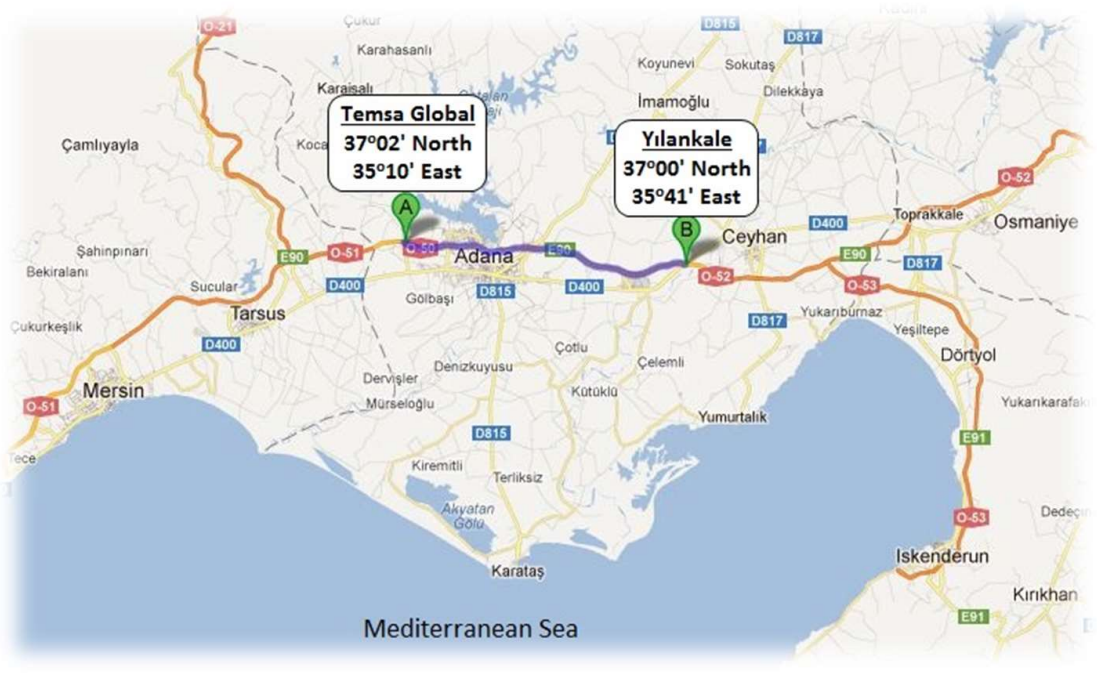

Figure 2. Details of the test route

The route followed during the experimental study is in the form of Temsa-Yllankale-Temsa as shown in Figure 2. The distance of Temsa-Yllankale is about $50 \mathrm{~km}$. In this route, experimental study lasted until the internal temperatures reach to the steady state. To reach the steady state condition of the system has been in about 120 minutes. 


\section{EXPERIMENTAL DATA AND CALCULATIONS}

Cooling load calculations were made by using the RTS method. The bus has a 61 passenger capacity plus two staff, so cooling load calculations should be made according to a total of 63 people. In the calculations, the external temperature and relative humidity were taken as $35^{\circ} \mathrm{C}$ and $45 \%$, respectively. The comfort zone for the summer season is defined according to ASHRAE [10], as shown in the Fig. 3. Accordingly, the internal temperature and relative humidity were taken as $25^{\circ} \mathrm{C}$ and $50 \%$, respectively.

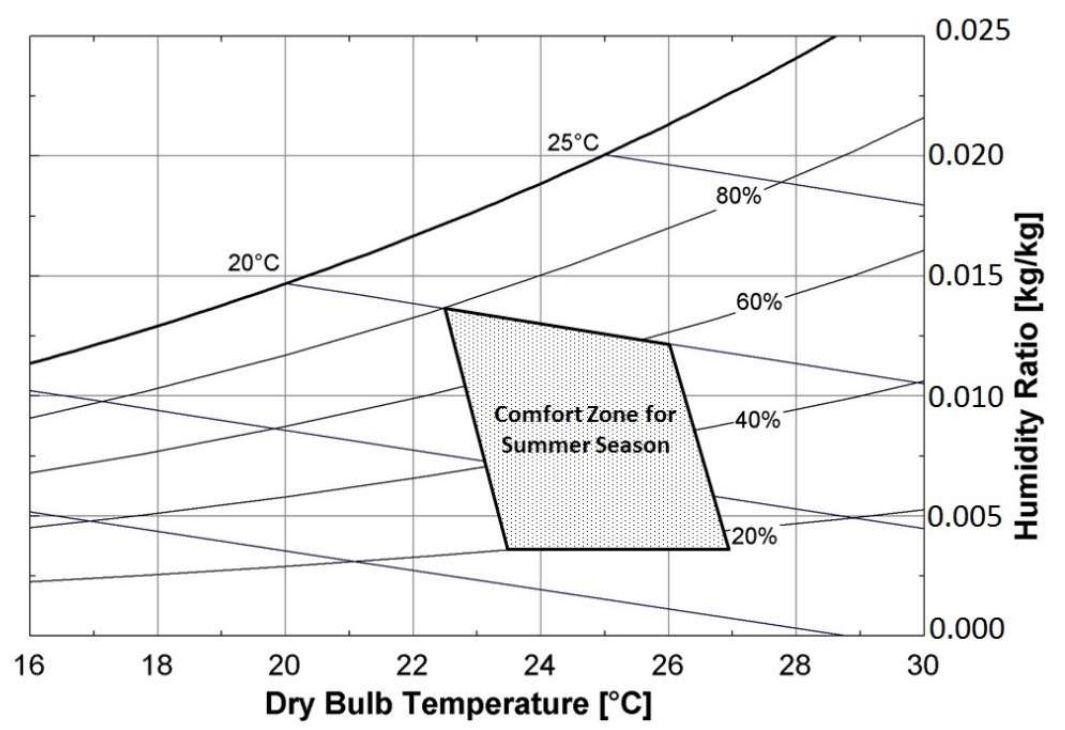

Figure 3. Comfort zone defined by ASHRAE for summer season

Variation of the calculated cooling load during the day is shown in Fig. 4. This cooling load was obtained according to maximum passenger capacity. In the cooling load calculation, sensible and latent heat gain for people given by ASHRE [9] were taken as $75 \mathrm{~W}$ and $55 \mathrm{~W}$ per one person, respectively. In addition, 10W cooling loads per one person were added because of their clothes. Also, outdoor air requirement for ventilation of the bus was assumed as $20 \mathrm{~m}^{3} \mathrm{~h}^{-1}$ per one person according to the ASHRAE[21]. So, the maximum cooling load was calculated as $30.5 \mathrm{~kW}$. This cooling load is derived from surfaces $(8 \mathrm{~kW}, 26 \%)$, ventilation $(10 \mathrm{~kW}, 33 \%)$, people $(8.82 \mathrm{~kW}, 29 \%)$, infiltration $(2.33 \mathrm{~kW}, 8 \%)$, and equipment $(1.35 \mathrm{~kW}, 4 \%)$. Accordingly, an air conditioning providing a $32.5 \mathrm{~kW}$ cooling capacity was selected for the bus.

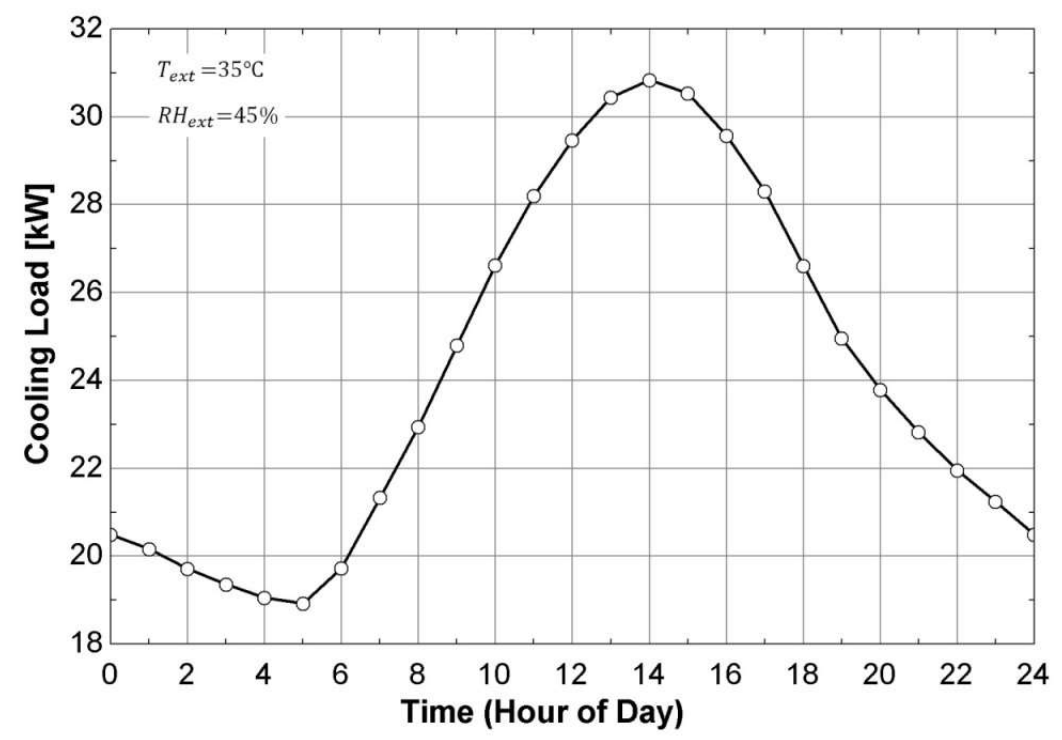

Figure 4. Variation of the cooling load according to maximum passenger capacity during the day 
The results obtained from experiments were evaluated according to the ASHARE [12] thermal sensation scale given in Fig. 5. The empirical equations given by ASHRAE [11] are shown below to calculate thermal sensation values for men, women or both sexes.

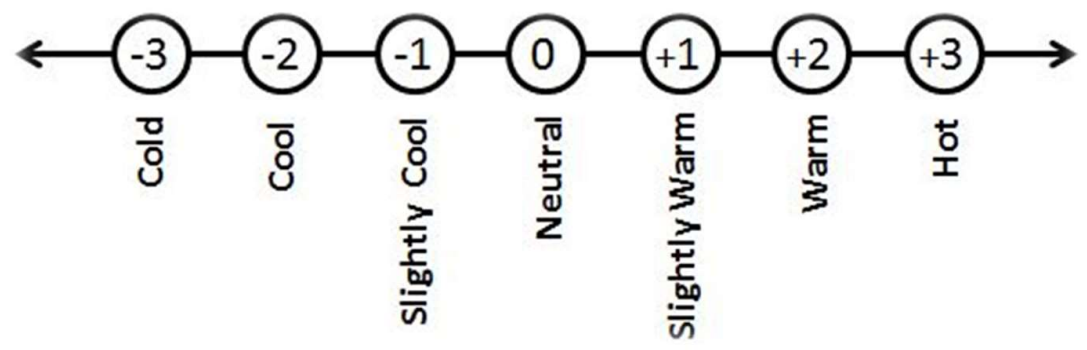

Figure 5. ASHRAE thermal sensation scale

$$
\begin{aligned}
& Y_{\text {men }}=0.221 T_{\text {int }}+0.27 P_{w s}-6.024 \\
& Y_{\text {women }}=0.283 T_{\text {int }}+0.21 P_{w s}-7.694 \\
& Y_{\text {both }}=0.252 T_{i n t}+0.24 P_{w s}-6.859
\end{aligned}
$$

External temperatures were measured at locations near the outside rearview mirrors on both sides of the bus. Variations in the external temperatures are shown in Fig. 6 as a function of time. The empirical equation for the arithmetic average of temperatures $T_{1}$ and $T_{2}$ is given in Eq. (4). The external temperature variations are also shown in Fig. 6 according to Eq. (4) as a function of time.

$$
T_{\text {ext }, \text { avrg }}=33.4-0,011 \cdot t
$$

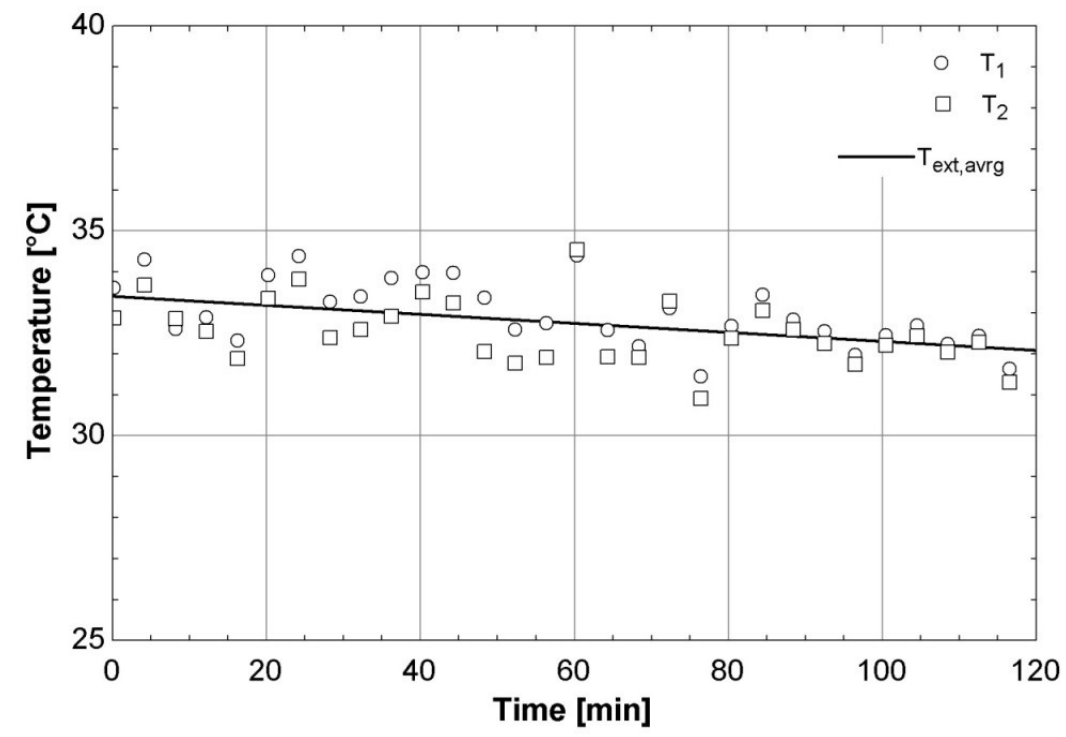

Figure 6. Variation of the external temperatures with time during the experiment

The internal temperatures were measured at ten different locations labeled as $T_{3} \sim T_{12}$ in Fig. 1. Variations in the internal temperatures are shown in Fig. 7 as a function of time. The empirical equation for the arithmetic 
average of temperatures $T_{3} \sim T_{12}$ is given in Eq. (5). The internal temperature variations are also shown according to Eq. (5) as a function of time.

$T_{\text {int, avrg }}=56.5-7.35 \cdot \ln (t)$

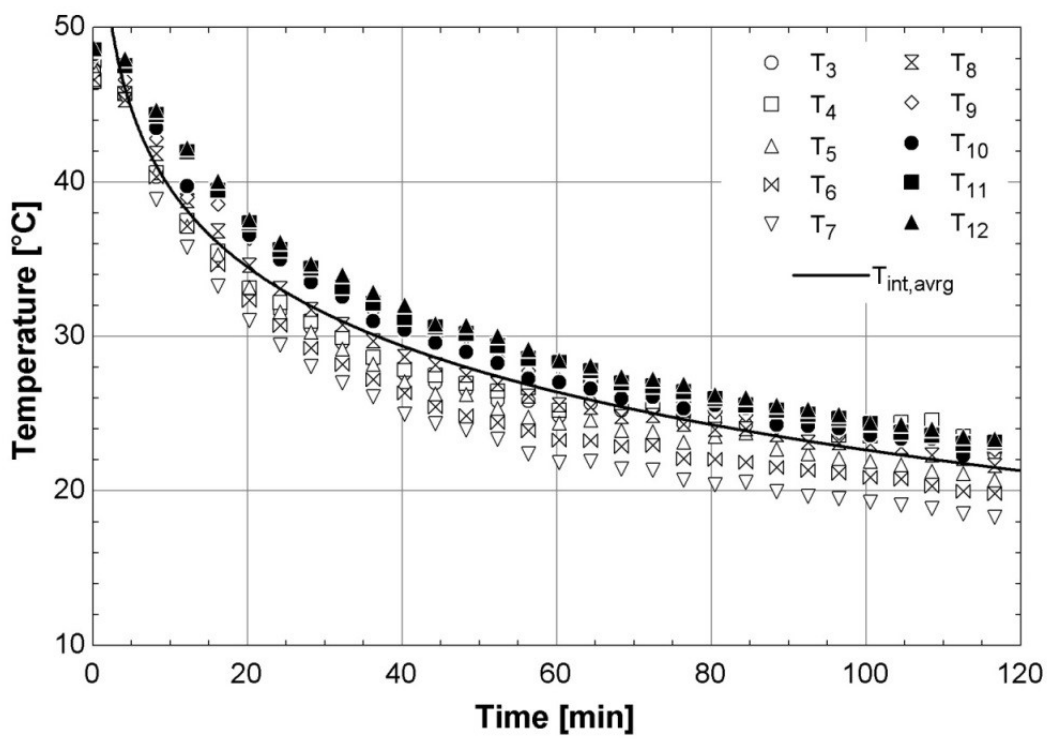

Figure 7. Variation of the internal temperatures with time during the experiment

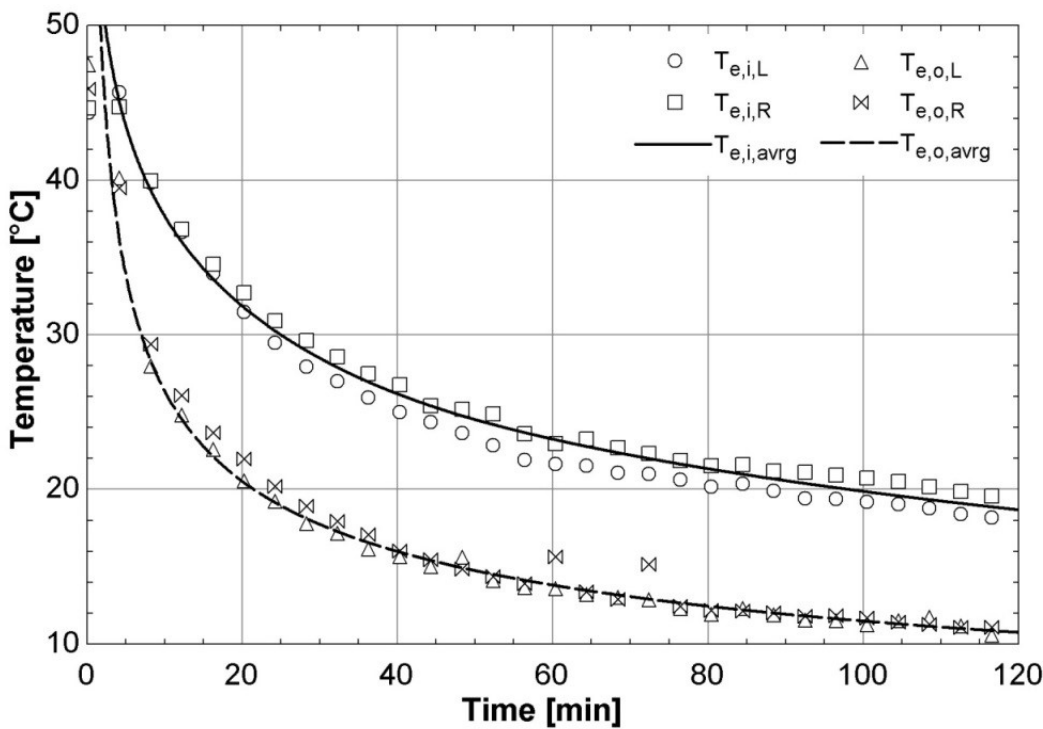

Figure 8. Variation of the temperatures at the evaporator inlet and outlet with time during the experiment

The air conditioning system is mounted on the ceiling of the bus. The system has two separate evaporator units, one on each side of the bus. Variations in the temperatures at the inlet and outlet of the evaporator units are shown in Fig. 8 as a function of time. The empirical equations given in Eq. (6) and (7) can be used to determine the arithmetic average of the temperatures at each evaporator inlet and outlet. Temperature values obtained by using Eq. (6) and (7) are also shown in Fig. 8.

$T_{e, i, a v r g}=\left\{[50-6.548 \cdot \ln (t)]^{80}+[57-8.4 \cdot \ln (t)]^{80}\right\}^{(1 / 80)}$ 
$T_{e, o, a v r g}=e^{4.1-0.36 \cdot \ln (t)}$

Relative humidity values of the air at each evaporator inlet and outlet were measured in real time. Variations in these relative humidity values are shown as a function of time in Fig. 9. The empirical equations for the relative humidity at each evaporator inlet and outlet are given in Eq. (8) and (9), respectively. The variation in relative humidity values at each evaporator inlet and outlet are shown in Fig. 9 according to Eq. (8) and (9) as a function of time.

$$
\begin{aligned}
& \emptyset_{e, i}=43.03+0.057 \cdot t \\
& \emptyset_{e, o}=\left\{[70+2.1 \cdot \ln (t)]^{-50}+[50+8.5 \cdot \ln (t)]^{-50}\right\}^{(-1 / 50)}
\end{aligned}
$$

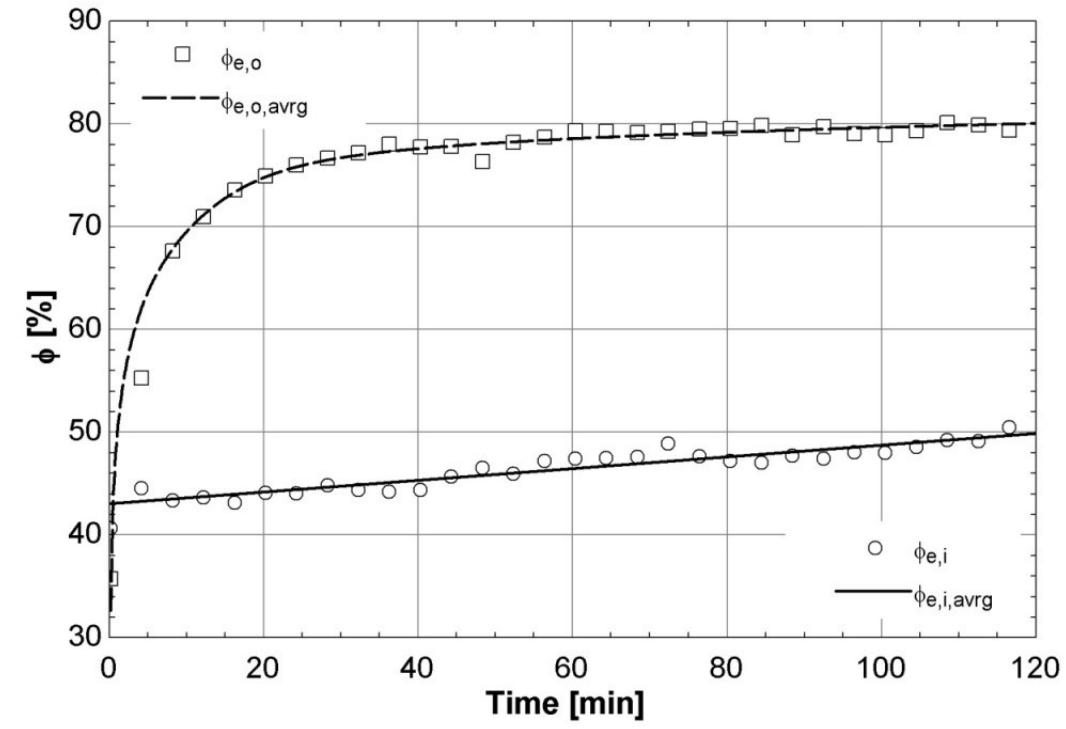

Figure 9. Variation of the relative humidity values at the evaporator inlet and outlet with time during the experiment

The instantaneous cooling load of the air conditioning system was calculated by using the following equation.

$$
\dot{Q}=\rho \cdot \dot{V} \cdot\left(h_{e, i}-h_{e, o}\right)
$$

Each evaporator has three unit air blowers and each one has $1020 \mathrm{~m}^{3} \mathrm{~h}^{-1}$ flow rate. Therefore, the total air flow rate of the air conditioning system is $6120 \mathrm{~m}^{3} \mathrm{~h}^{-1}$. This flow rate is valid without any counter pressure. During testing, the total air flow rate passing through the evaporator fins was measured to be $4950 \mathrm{~m}^{3} \mathrm{~h}^{-1}$.

Density of the air at the evaporator outlet was calculated by using Eq. (11) [15].

$\rho=\frac{348.1}{T_{e, o}+273}$

Enthalpies of the air at the evaporator inlet and outlet can be calculated by using the measured temperature and relative humidity values. The empirical equation given in Eq. (12) was used to calculate the moist air enthalpy [15].

$h=C_{p, a} \cdot T+w \cdot h_{w s}$ 
Specific heat capacity of the air was assumed to be $1.007 \mathrm{~kJ} \mathrm{~kg}^{-1} \mathrm{~K}^{-1}$. The enthalpy of the water vapor in humid air was calculated by the empirical equation given below [15].

$h_{w s}=2501.6+\left(1.855+2.2147 \cdot 10^{-4} \cdot T\right) \cdot T$

Eq. (14) was used to determine the humidity ratio of moist air [11].

$$
w=0.622 \cdot \frac{\emptyset \cdot P_{w s}}{100 \cdot P-\emptyset \cdot P_{w s}}
$$

$\mathrm{P}$ indicates the atmospheric pressure. Pressure of the saturated water vapor $P_{w s}$ was calculated by using the empirical equations given in Eq. (15) (21) [15].

$$
\begin{aligned}
& P^{*}=P_{1}^{*}+P_{2}^{*}-\frac{1}{P_{3}^{*}+P_{4}^{*}} \\
& P^{*}=P_{w s} / P_{c r} \\
& T^{*}=\frac{T+273}{T_{c r}+273} \\
& P_{1}^{*}=533.83 \cdot e^{5.897 /\left(0.07086-T^{*}\right)} \\
& P_{2}^{*}=107 \cdot 10^{6} \cdot e^{-21.18 / T^{*}} \\
& P_{3}^{*}=10^{19} \cdot e^{-11.8 / T^{*}} \\
& P_{4}^{*}=3 \cdot 10^{-4} \cdot e^{8.56 / T^{*}}
\end{aligned}
$$

So, the thermal sensation values and the instantaneous cooling load of the air conditioning system were calculated by using the measured data.

\section{UNCERTAINTY ANALYSIS}

The thermal sensation values for man, women, and both sexes were calculated by using Eq.(1) (3), respectively. For this calculation, we need only internal temperature values of the locations shown in the Fig. 1. The uncertainty in the thermal sensation values were calculated by using Eq. (22):

$$
\frac{\delta Y}{Y}=\sqrt{\left(\frac{\delta T_{i n t}}{T_{\text {int }}}\right)^{2}+\left(\frac{\delta P_{w s}}{P_{w s}}\right)^{2}}
$$

The uncertainty in the thermal sensation values can be expressed as a function of measured parameter as follows:

$$
\frac{\delta Y}{Y}=\sqrt{\left(\frac{\delta T_{i n t}}{T_{i n t}}\right)^{2}+\left(\frac{\delta T_{i n t}}{T_{i n t}}\right)^{2}}=\sqrt{2}\left(\frac{\delta T_{i n t}}{T_{i n t}}\right)
$$

The instantaneous cooling load of the air conditioning system was calculated by using Eq. (10). For this calculation, measured values of the temperature, relative humidity and flow rate of the air were used. Independent variables measured during the experiment and used in cooling load calculations are listed below: 
a) Air temperature at the evaporator inlet $\left(T_{e, i, L}, T_{e, i, R}\right)$

b) Air temperature at the evaporator outlet $\left(T_{e, o, L}, T_{e, o, R}\right)$

c) Relative humidity at the evaporator inlet $\left(\emptyset_{e, i}\right)$

d) Relative humidity at the evaporator outlet $\left(\varnothing_{e, o}\right)$

e) Air velocity of passing through the evaporator fins $(V)$

The instantaneous cooling load provided by Eq. (10) can be expressed as a function of measured parameters given in Eq. (24).

$$
\dot{Q}=f\left(T_{e, i, L}, T_{e, i, R}, T_{e, o, L}, T_{e, o, R}, \emptyset_{e, i}, \emptyset_{e, o}, V\right)
$$

Because of the measurement errors in the measured parameters, the law of propagation of uncertainties was used to determine of the total error for the instantaneous cooling load calculation as described in [22, 23]. The uncertainty in the instantaneous cooling load of the air conditioning system was calculated by using Eq. (25):

$\frac{\delta \dot{Q}}{\dot{Q}}=\sqrt{\left(\frac{\delta \rho}{\rho}\right)^{2}+\left(\frac{\delta \dot{V}}{\dot{V}}\right)^{2}+\left(\frac{\delta h_{i}}{h_{i}}\right)^{2}+\left(\frac{\delta h_{o}}{h_{o}}\right)^{2}}$

Each term in Eq. (24) can be expressed as a function of measured parameters shown in Eq. (26) (29).

$$
\begin{aligned}
& \left(\frac{\delta \rho}{\rho}\right)^{2}=\left(\frac{\delta T_{e, o, L}}{T_{e, o, L}}\right)^{2}+\left(\frac{\delta T_{e, o, R}}{T_{e, o, R}}\right)^{2} \\
& \left(\frac{\delta \dot{V}}{\dot{V}}\right)^{2}=\left(\frac{\delta V}{V}\right)^{2} \\
& \left(\frac{\delta h_{e, i}}{h_{e, i}}\right)^{2}=\left(\frac{\delta T_{e, i, L}}{T_{e, i, L}}\right)^{2}+\left(\frac{\delta T_{e, i, R}}{T_{e, i, R}}\right)^{2}+\left(\frac{\delta \emptyset_{e, i}}{\emptyset_{e, i}}\right)^{2} \\
& \left(\frac{\delta h_{e, o}}{h_{e, o}}\right)^{2}=\left(\frac{\delta T_{e, o, L}}{T_{e, o, R}}\right)^{2}+\left(\frac{\delta T_{e, o, R}}{T_{e, o, R}}\right)^{2}+\left(\frac{\delta \emptyset_{e, o}}{\emptyset_{e, o}}\right)^{2}
\end{aligned}
$$

Uncertainties of the thermal sensation values and instantaneous cooling load were calculated by using the accuracy values given in Table 1. Average errors in the thermal sensation values and instantaneous cooling load were calculated as $1.5 \%$ and $4.7 \%$, respectively.

\section{RESULTS AND DISCUSSION}

This experimental study was performed on the Adana-Ceyhan highway in August. The average external temperature was $33^{\circ} \mathrm{C}$ at the beginning; it was later measured to be $32^{\circ} \mathrm{C}$ towards the end of the experiment, as shown in Fig. 6. Unusually large fluctuations in the external temperature are reflections of places such as tunnels or when in heavy traffic. According to the Fig.6, it can be said that outside temperature is nearly constant during the experiment.

The internal temperatures were measured to be approximately $50^{\circ} \mathrm{C}$ at the beginning of the study, as shown in Fig. 7, as a result of the bus exposed to the sun for a long time prior to the start of the experiment. As evident, the internal temperatures decreased quickly after the air conditioning was activated. The average internal temperature decreased to the external temperature after approximately 20 minutes and then decreased to $25^{\circ} \mathrm{C}$, which is the desired comfort condition after approximately 60 minutes. The average internal temperature remained constant at $22^{\circ} \mathrm{C}$ after approximately 120 minutes indicating that the system had reached a steady state 
condition. The consistently lowest internal temperature was $T_{6}$. This thermocouple was located near the evaporator blowers. The warmest place within the internal environment was the engine room, represented by $T_{12}$. Due to the bus sun exposure prior to the start of the experiment, the temperature of the evaporator fins was also high to start. Furthermore, the air temperature at the evaporator outlet was actually higher than the air temperature at the evaporator inlet at the beginning of the experiment, as shown in Fig. 8 . The air temperature at the evaporator outlet dropped below that of the evaporator inlet after approximately 2 minutes. At the end of the experiment, i.e., steady state, the temperature difference between the evaporator inlet and outlet was approximately $10^{\circ} \mathrm{C}$. This means that it is sufficient temperature difference at the evaporator unit to make necessary cooling for internal environment of the bus.

In the beginning, while the relative humidity value at the evaporator inlet is nearly $43 \%$, and then it is $50 \%$ in steady-state condition as shown in Fig. 9. The relative humidity at the evaporator outlet is measured initially approximately $35 \%$. It is observed that the relative humidity at the evaporator outlet is rapidly increasing, and it is $80 \%$ in steady-state condition. According to the experimental results, the instantaneous cooling load increased rapidly in the first eight minutes, and it reached a maximum value, as shown in Fig. 10. It can be seen that the air conditioning system of the bus has reached approximately $32 \mathrm{~kW}$ of cooling capacity in the first 20 minutes. The experimental study was made with 3 person, and after reaching steady state, the cooling load was obtained as about $22 \mathrm{~kW}$. Accordingly, it is clear that the air conditioning system of the bus has the required cooling capacity, if the bus has maximum passenger capacity.

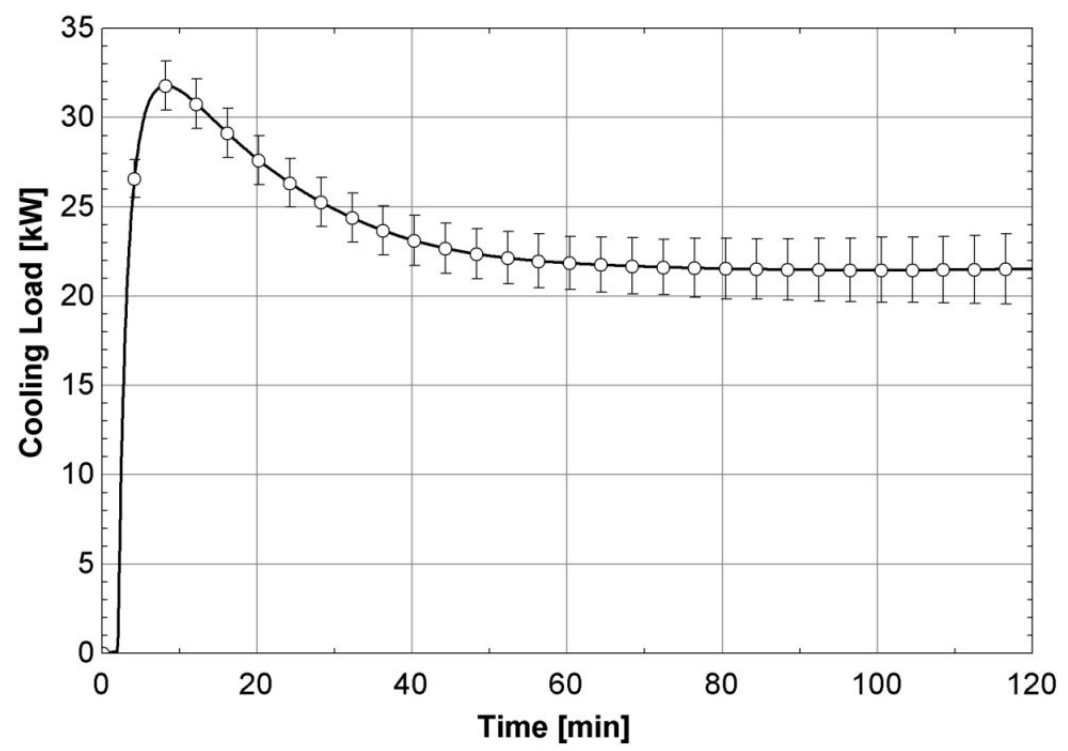

Figure 10. Variation of the instantaneous cooling load of the air conditioning with time during the experiment

Variation of the thermal sensation values for men, women and both sexes with time during the experiments are shown in Fig. 11, 12 and 13, respectively. In these figures, thermal sensation values are given for the passengers seated at the points shown in Fig.1 as (3)-(12). Accordingly, after the system reaches steady state, the lowest thermal sensation values are obtained at the mid-points of bus. This is because; evaporator units of the air-conditioning are located at the midpoint of the bus. Due to the evaporator units are positioned at the middle of the bus, cold air in the duct is given to the internal environment at the lower temperature than the other locates. Accordingly, the thermal sensation values at the midpoints are calculated as lower than the other points. Also, the maximum thermal sensation values are obtained at the rear of the bus. The reason for this situation, engine of the bus is located at the rear of the bus and cold air in the duct is warming through the channel. 


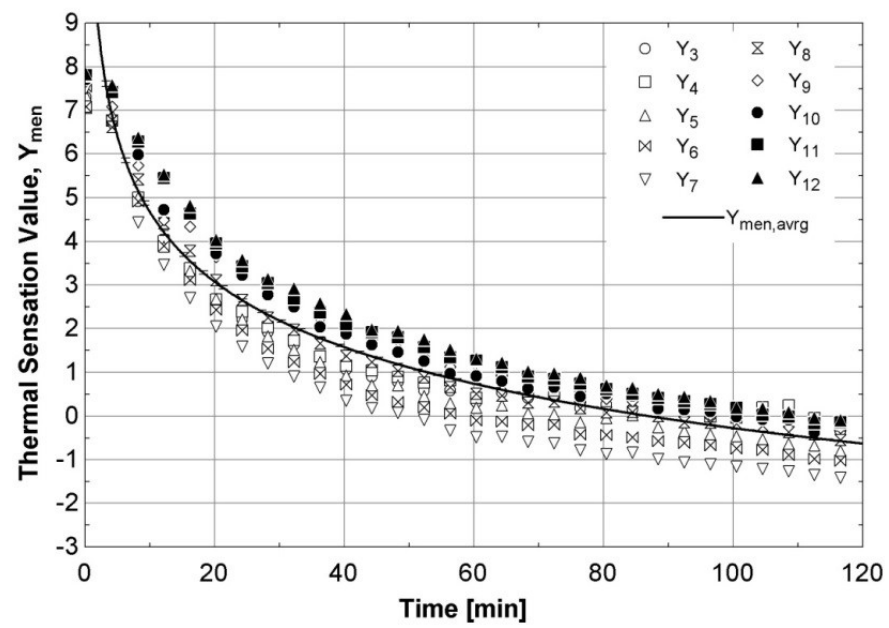

Figure 11. Variations of the thermal sensation values for men with time during the experiment

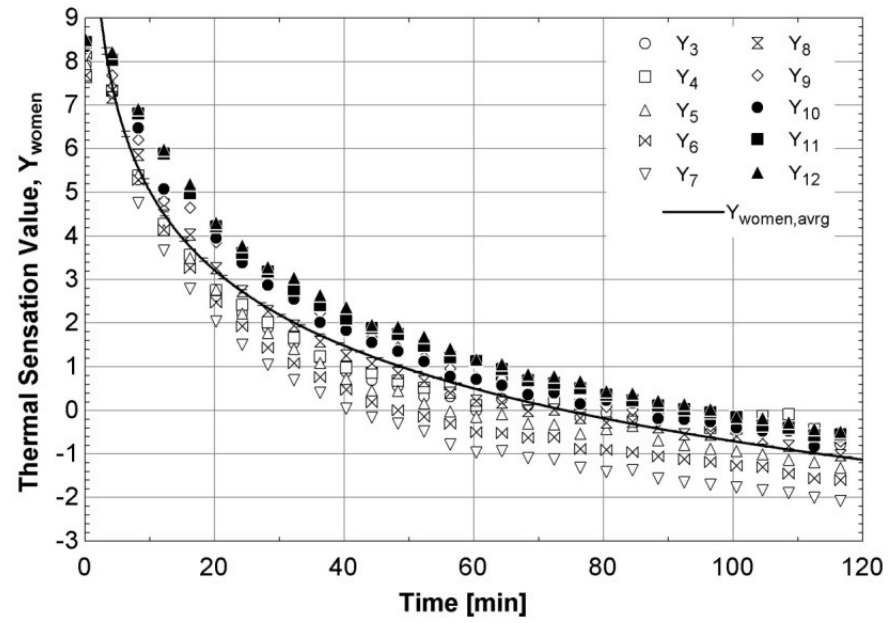

Figure 12. Variations of the thermal sensation values for women with time during the experiment

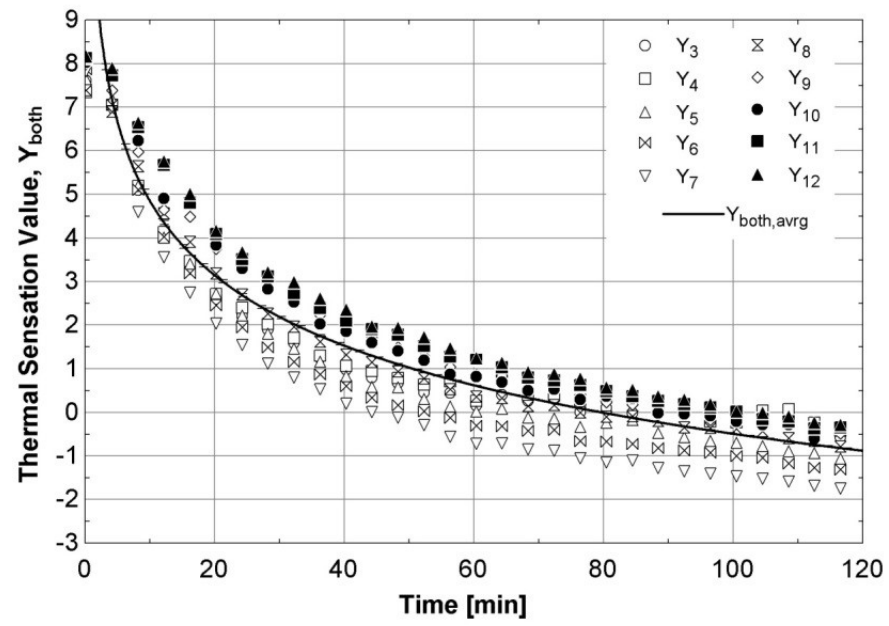

Figure 13. Variations of the thermal sensation values for both sexes with time during the experiment 


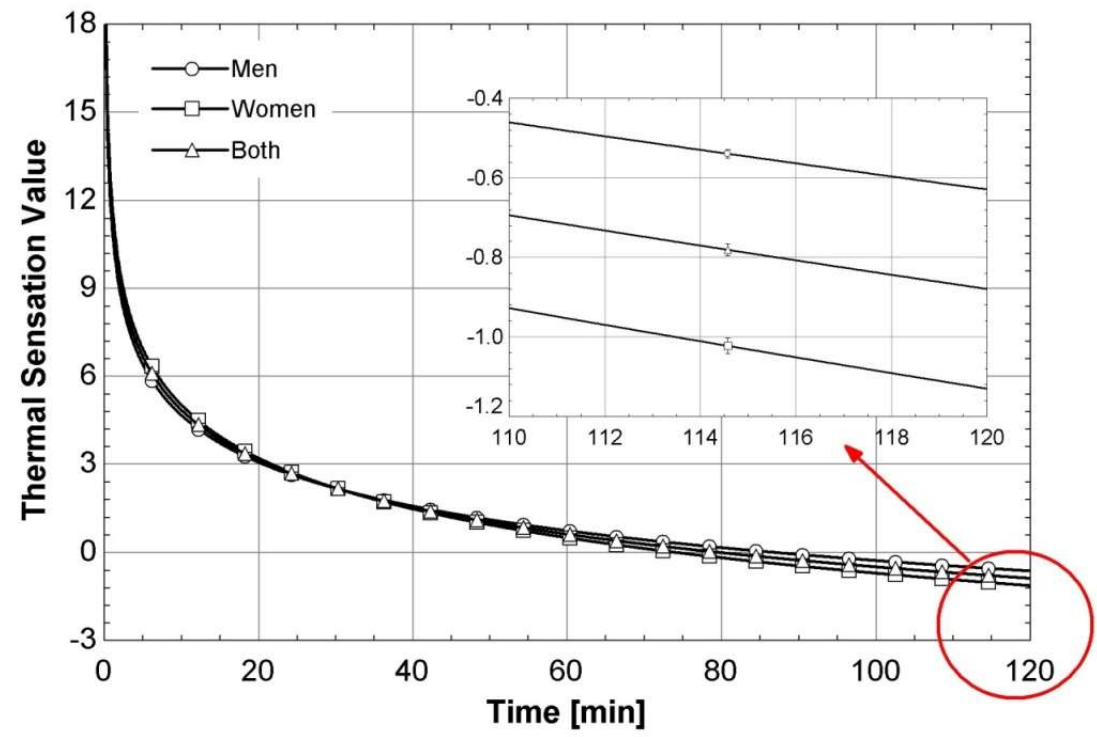

Figure 14. Variations of the thermal sensation values with time during the experiment

Thermal sensation values were initially notably high, as shown in Fig. 14. This value decreased to +3, which is the maximum value given in the ASHRAE thermal sensation scale, after approximately 20 minutes; it fell to zero 80 minutes later. Thermal sensation values for men and women were -0.6 and -0.85 during steady state, respectively. Accordingly, it can be said that the internal environment would have been perceived as slightly cool. Therefore, it is concluded that the air conditioning system performed satisfactorily in terms of thermal sensation values.

\section{CONCLUSIONS}

1) There are not any experimental data about the bus air conditioning system in the open literature. In this work, all the experimental results are provided including external and internal temperatures, temperatures and relative humidity values at the inlet and outlet of the evaporator.

2) Using the method explained in this work, it is possible to determine whether a selected air conditioning system meets its design and comfort requirements through on-vehicle prototype testing.

3) Intercity buses often park in parking areas that are exposed to direct sunlight. Consequently, internal bus temperatures may reach $60^{\circ} \mathrm{C}$ in regions with warmer climates, such as Adana. Such a high temperature should be reduced before the traveling. As shown by Fig. 8, the variation in the average internal temperature decreased to the external temperature in 20 minutes. Therefore, it can be said that the air conditioning should be run for at least 30 minutes before traveling.

\section{ACKNOWLEDGMENTS}

This study is supported by TEMSA Global Industry and Trade Inc. The author would like to thank TEMSA Global for their contributions.

\section{NOMENCLATURE}

$C_{p a} \quad$ Specific heat capacity of air, $\mathrm{kJ} \mathrm{kg}^{-1} \mathrm{~K}^{-1}$

$h \quad$ Enthalpy, $\mathrm{kJ} \mathrm{kg}^{-1}$

$P \quad$ Pressure, $\mathrm{kPa}$

$\dot{Q} \quad$ Cooling load, $\mathrm{kW}$

$t \quad$ Time, min.

$T \quad$ Temperature, ${ }^{\circ} \mathrm{C}$

$\dot{V} \quad$ Volumetric flow rate, $\mathrm{m}^{3} \mathrm{~s}^{-1}$

$w \quad$ Humidity ratio, $\mathrm{kg} \mathrm{kg}^{-1}$ 


$\begin{array}{ll}Y & \text { Thermal sensation value } \\ \rho & \text { Density, } \mathrm{kg} \mathrm{m}^{-3} \\ \varnothing & \text { Relative humidity, \% } \\ \text { Subscripts } \\ \text { avrg } & \text { Average } \\ c r & \text { Critical point } \\ e & \text { Evaporator } \\ \text { ext } & \text { External } \\ g & \text { Grill } \\ i & \text { Inlet } \\ \text { int } & \text { Internal } \\ o & \text { Outlet } \\ w s & \text { Saturated vapor }\end{array}$

\section{REFERENCES}

[1] M. Hegar M., M. Kolda, M. Kopecka, V. Rajtmajer, A. Ryska, Bus HVAC energy consumption test method based on HVAC unit behavior, International Journal of Refrigeration, 36 (2013) 1254-1262.

[2] Ç. Kutlu, Ş. Ünal, M.T. Erdinç, Thermodynamic analysis of bi-avaporater ejector refrigeration cycle using R744 as natural refrigerant, Journal of Thermal Engineering, 2(2) (2016), 735-740.

[3] P. Maina, Z. Huan, Effects of various parameters on the efficiency of a $\mathrm{CO}_{2}$ heat pump: A statistical approach, Journal of Thermal Engineering, 1(4) (2015), 263-278.

[4] ASHRAE Applications Handbook SI, American Society of Heating, Refrigerating and Air-Conditioning Engineers Inc., Atlanta, GA, USA, (2003).

[5] B.T. Jaime, F. Bjurling, J.M. Corberan, F.D. Sciullo, J. Paya, Transient thermal model of a vehicle's cabin validated under variable ambient conditions, Applied Thermal Engineering, 75 (2015) 45-53.

[6] O. Solmaz, M. Ozgoren, M.H. Aksoy, Hourly cooling load prediction of a vehicle in the southern region of Turkey by Artificial Neural Network, Energy Conversion and Management, 82 (2014) 177-187.

[7] K.W. Mui, L.T. Wong, Cooling Load Calculations in Subtropical Climate, Building and Environment, 42 (2007) 2498-2504.

[8] M.K. Mansour, M.N. Musa, M.N.W. Hassan, K.M. Saqr, Development of novel strategy for multiple circuit, roof top bus air conditioning system in hot humid countries, Energy Conversion and Management, 49 (2008) 1455-1468.

[9] Ö. Kaynaklı, I. Horuz, An experimental analysis of automotive air conditioning system, Int.Comm. Heat Mass Transfer, 30 (2003) 273-284.

[10] O. Büyükalaca, T. Yılmaz, Ş. Ünal, E. Cihan, E. Hürdoğan, Calculation of cooling load of a bus using radiant time series (RTS) method, 6th International Advanced Technologies Symposium (IATS'11), Elazığ/Turkey, 16-18 May (2011) 227-230 (in Turkish).

[11] ASHRAE Fundamentals Handbook, American Society of Heating, Refrigerating and Air-Conditioning Engineers Inc., Atlanta, GA, USA, (2001).

[12] ASHRAE Standard 55, Thermal environmental conditions for human occupancy, American Society of Heating, Refrigerating and Air-Conditioning Engineers Inc., Atlanta, GA, USA, (2004).

[13] K.W. Shek, W.T. Chan, Combined comfort model of thermal comfort and air quality on buses in Hong Kong, The Science of the Total Environment, 9 (2008) 277-282.

[14] H. Zhang, L. Dai, G. Xu, Y. Li, W. Chen, W. Tao, Studies of air-flow and temperature fields inside a passenger compartment for improving thermal comfort and saving energy. Part I: Test/numerical model and validation, Applied Thermal Engineering, 29 (2009) 2022-2027.

[15] H. Zhang, L. Dai, G. Xu, Y. Li, W. Chen, W. Tao, Studies of air-flow and temperature fields inside a passenger compartment for improving thermal comfort and saving energy. Part II: Simulation results and discussion, Applied Thermal Engineering, 29 (2009) 2028-2036.

[16] A. Alahmer, A. Mayyas, A.A. Mayyas, M.A. Omar, D. Shan, Vehicular thermal comfort models; a comprehensive review, Applied Thermal Engineering, 31 (2011) 995-1002. 
[17] A. Alahmer, M. Abdelhamid, M. Omar, Design for thermal sensation and comfort states in vehicles cabins, Applied Thermal Engineering, 36 (2012) 126-140.

[18] R. Guofeng, T. Feng, Y. Lin, The research of thermal design for vehicle controller based on simulation, Applied Thermal Engineering, 58 (2013) 420-429.

[19] D. Marcos, F.J. Pino, C. Bordons, J.J. Guerra, The development and validation of a thermal model for the cabin of a vehicle, Applied Thermal Engineering, 66 (2014) 646-656.

[20] T. Yılmaz, Ş. Ünal, E. Cihan, Computational analysis of moist air processes. Proceedings of the Third National Congress of Refrigeration and Air Conditioning, Adana/Turkey, (1994) 325-332 (in Turkish).

[21] ASHRAE Standard 62, Ventilation for acceptable indoor air quality, American Society of Heating, Refrigerating and Air-Conditioning Engineers Inc., Atlanta, GA, USA, (2001).

[22] I. Lira, Evaluating the measurement uncertainty: Fundamentals and Practical Guidance. Taylor \& Francis, 2002.

[23] R.J. Moffat, Describing the uncertainties in experimental results. Experimental Thermal and Fluid Science, 1 (1988) 3-17. 